\title{
Effect of the use of a surgical guide on heat generation during implant placement: A comparative in vitro study
}

\author{
Khaldoun Hossein Alhroob ${ }^{1, A-D, F}$, Mohammed Monzer Alsabbagh ${ }^{1, A, B, E, F}$, Aghiad Yassin Alsabbagh ${ }^{2, A, C, E, F}$ \\ ${ }^{1}$ Department of Periodontology, Faculty of Dentistry, Damascus University, Syria \\ ${ }^{2}$ Salisbury District Hospital, UK \\ A - research concept and design; $\mathrm{B}$ - collection and/or assembly of data; $\mathrm{C}$ - data analysis and interpretation; \\ $D$ - writing the article; $E$ - critical revision of the article; $F$ - final approval of the article
}

Address for correspondence

Aghiad Yassin Alsabbagh

E-mail: aghiad88@gmail.com

Funding sources

None declared

Conflict of interest

None declared

Received on June 30, 2020

Reviewed on August 15, 2020

Accepted on September 17, 2020

Published online on March 22, 202

Cite as

Alhroob KH, Alsabbagh MM, Alsabbagh AY. Effect of the use of a surgical guide on heat generation during implant placement: A comparative in vitro study. Dent Med Probl. 2021;58(1):55-59. doi:10.17219/dmp/127605

DOI

$10.17219 / \mathrm{dmp} / 127605$

Copyright

( 2021 by Wroclaw Medical University

This is an article distributed under the terms of the

Creative Commons Attribution 3.0 Unported License (CC BY 3.0)

(https://creativecommons.org/licenses/by/3.0/).

\begin{abstract}
Background. Heat generation is considered a decisive factor in the occurrence of bone necrosis during implant placement, which can happen when the temperature exceeds a threshold of $47^{\circ} \mathrm{C}$ for 1 min. The use of a surgical guide to aid implant placement has gained popularity in the last few years. Whether it increases the risk of bone necrosis is still debatable.

Objectives. The aim of the present study was to compare heat generation during implant placement with and without the use of a surgical guide.

Material and methods. The study sample consisted of 80 measurement sites placed near 40 dental implant sockets, which were prepared on 10 bone-like dental models. These models were divided into 5 models for the conventional method group and 5 models for the surgical guide group. Each model had 4 implant sockets prepared, and then two 1-millimeter-wide holes were drilled $<1 \mathrm{~mm}$ away from the socket on the opposite sides of the implant socket to be used as temperature measurement sites. The diameter of the drill was standardized to $2.2 \mathrm{~mm}$, and 4 different drill lengths were used $(6,8,10$, and $12 \mathrm{~mm})$. The data was analyzed using the SPSS for Windows software, v. 13.0. A $p$-value of $<0.05$ was deemed statistically significant.
\end{abstract}

Results. Significant differences were found in heat generation between the conventional group $\left(41.07^{\circ} \mathrm{C}\right)$ and the surgical guide group $\left(42.97^{\circ} \mathrm{C}\right)(p<0.05)$. Significant changes in temperature were recorded after drilling, regardless of the method used $(p<0.05)$. Moreover, the length of the drill was associated with temperature changes, with longer drills generating more heat $(p<0.05)$.

Conclusions. Within the limitations of this study, the use of a surgical guide resulted in higher temperatures as compared to the conventional method of implant placement. However, the highest recorded temperature was far below the threshold for bone necrosis.

Key words: dental implants, bone, temperature 


\section{Introduction}

Dental implants have become an essential part of routine dental treatment to replace lost teeth. The conventional dental implant placement procedure involves making a surgical incision into the gingiva on the crest of the alveolus and elevating a mucoperiosteal flap to access the bone underneath it, then placing the dental implants, replacing the flap, and finally suturing the wound. ${ }^{1,2}$

Recently, flapless dental implant placement has gained popularity as an alternative to the conventional dental implant placement procedure with many advantages, such as being less invasive, possibly causing less postsurgical discomfort, shortening the duration of the surgical procedure, and minimizing changes that occur in the alveolar crest. This might be attributed to a relatively small surgical incision and not raising a mucoperiosteal flap. ${ }^{3-5}$

Moreover, various computer-guided systems are now available to help in making a precise three-dimensional (3D) diagnosis, and the programs included in these systems aid in accurately transferring the locations of virtual implants from the computer to appropriate sites in the patient's mouth. The necessity for this accuracy has become more prominent, especially after the adoption of computerguided systems in flapless implantation procedures. ${ }^{6}$

The effectiveness of surgical guides remains a topic for scientific research, especially given what some studies suggest regarding the effectiveness of using surgical guides with irrigation cooling. This is a crucial point, as exposing bone tissue to a temperature of $47^{\circ} \mathrm{C}$ for a full minute is considered a threshold for causing irreversible osteonecrosis, which necessitates taking measures to avoid subjecting the bone to mechanical or thermal damage. ${ }^{7,8}$

Therefore, the aim of our study was to compare changes in bone temperature while preparing the implant site with the use of a surgical guide and by means of the conventional method of implantation. Moreover, we assessed the effects of using various drill lengths on heat generation.

\section{Material and methods}

A comparative laboratory study was conducted to assess an increase in temperature when using either the conventional method or a surgical guide for dental implant placement. The study was carried out between December 2019 and March 2020.

The study sample consisted of 80 measurement sites placed near 40 dental implant sockets, which were prepared on 10 artificial-boneblocks similar to human D2 bone (solid rigid polyurethane foam; Alexandria Industries, Taipei, Taiwan). These models were divided into 5 models for the conventional method group and 5 models for the surgical guide group (Fig. 1). Each model had 4 implant sockets prepared, and then two 1-millimeter-wide holes were drilled $1 \mathrm{~mm}$ away from the socket on the opposite sides of the implant socket to be used as temperature measurement sites (Fig. 2). The holes were drilled using Peeso reamers (Rogin Dental, Shenzhen, China) on a contra-angle handpiece (NSK, Tokyo, Japan) (Fig. 3).

Each bone block was placed in an aqueous medium of a temperature similar to body temperature $\left(37^{\circ} \mathrm{C}\right),{ }^{9}$ then a thermometer (Thermocouple Type $\mathrm{K}$ device; Danoplus, Hong Kong, China) was placed inside the measurement sites and the temperature was recorded (Fig. 4). The implant motor (X-Cube implant motor system; Dentis, Daegu, South Korea) was set to 1,200 rpm, $30 \mathrm{~N}$ and $85 \%$ irrigation for the preparation of all implant sites.

Drilling was started for the implant socket with a 6-millimeter-long bur of a diameter of $2.2 \mathrm{~mm}$ (Dentis) and the temperature was recorded immediately after drilling in the temperature measurement sites. The temperature was also recorded before and immediately after drilling with the use of 8-, 10- and 12-millimeter-long drills. The same procedure was applied in the surgical guide group, following the insertion of the customized surgical guide.

Having collected the data, it was entered and analyzed using the SPSS for Windows software, v. 13.0 (SPSS, Inc., Chicago, USA). The statistical analysis was conducted

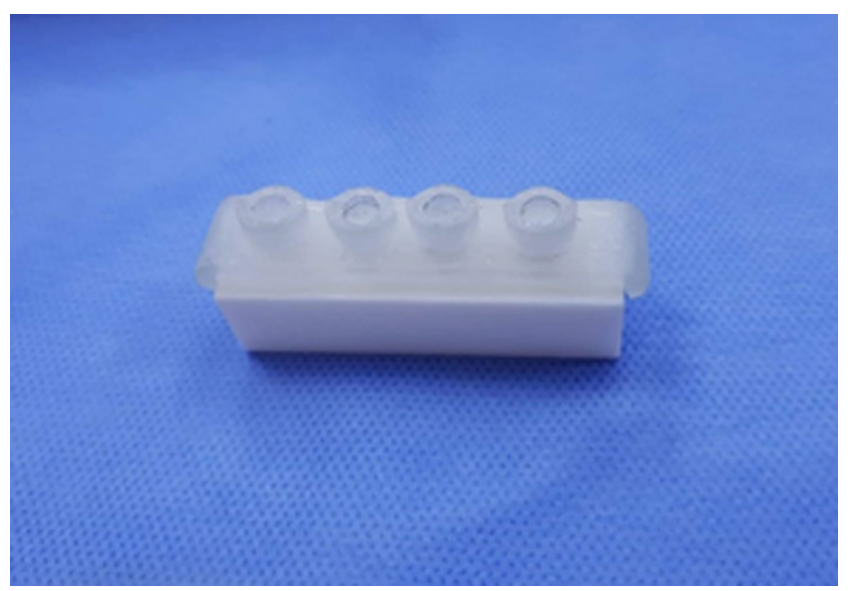

Fig. 1. Bone model with the surgical guide mounted

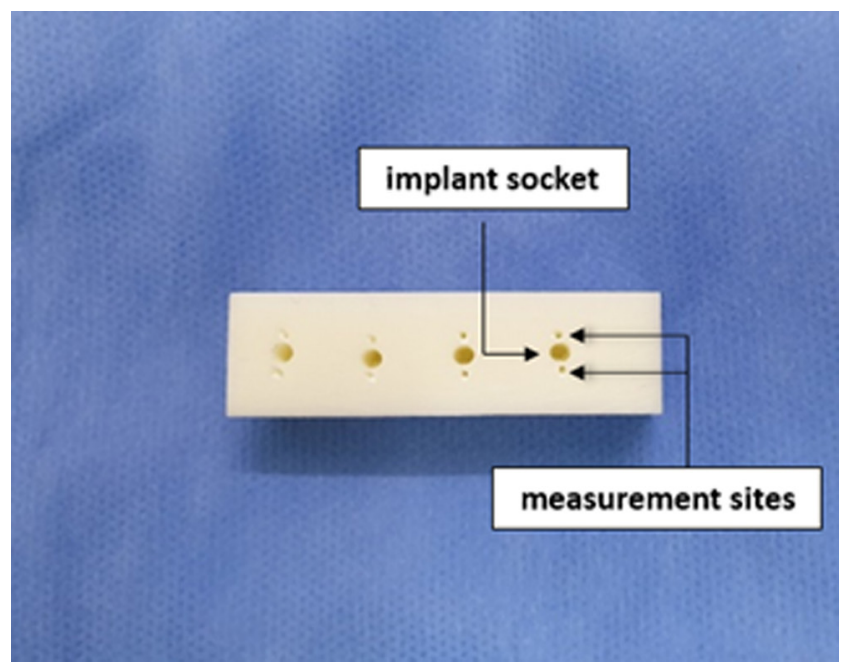

Fig. 2. Bone model showing the implant sockets and the temperature measurement sites 


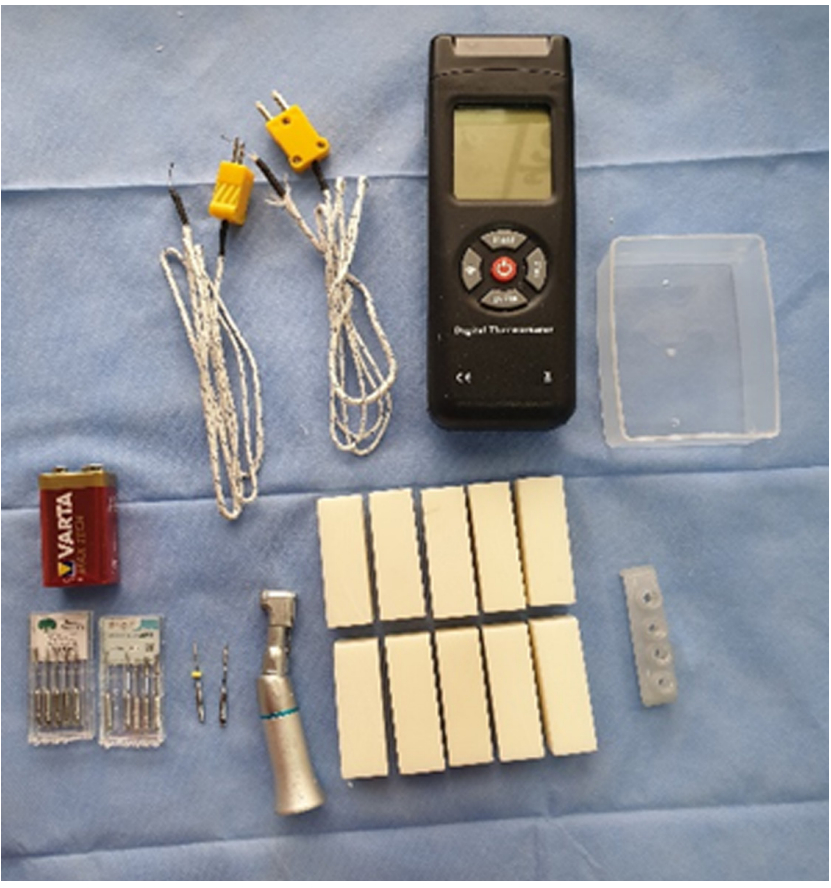

Fig. 3. Laboratory materials (from left to right): a battery, Peeso reamers, a contra-angle handpiece, cords, a thermometer, bone blocks, water, and a surgical guide

at the significance level set at $0.05(p<0.05)$. The analysis of variance (ANOVA) was used to determine the existence of statistically significant differences when comparing more than 2 independent variables, and the Bonferroni correction was used to perform multiple comparisons. The mean temperature of all measurement sites was used to study the different variables, except for the temperature differences between the 2 measurement sites, where the comparison was made between the means of the opposite sides.

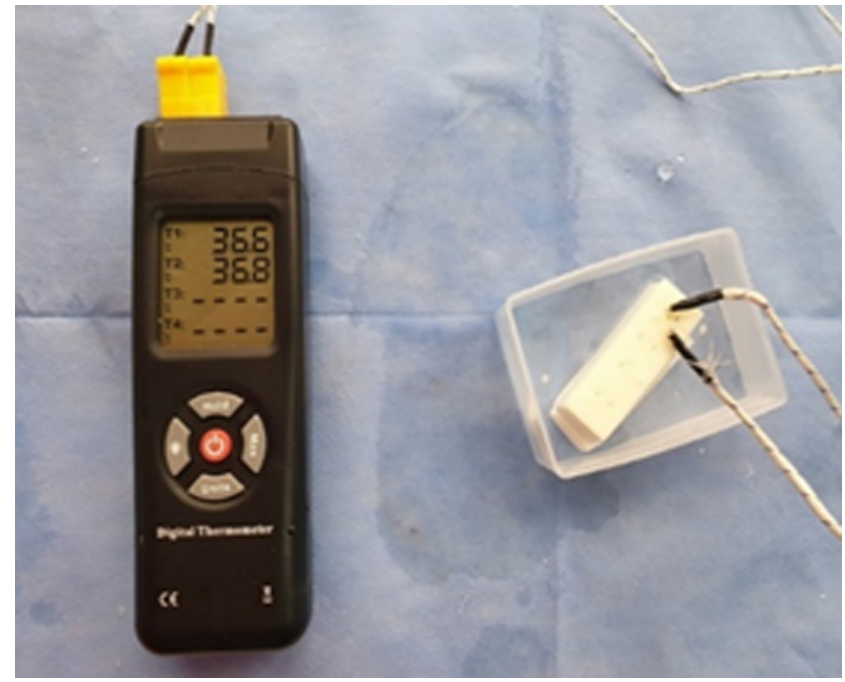

Fig. 4. Temperature recorded in 2 measurement sites

\section{Results}

The study sample consisted of 80 measurement sites for 40 dental implant locations (orthopedic pits), which were prepared on 10 artificial-bone blocks.

Table 1 shows the sample temperature before and immediately after drilling with regard to the following variables: implant placement method; drill length; and measurement site.

The mean temperature in the surgical guide group was $38.14^{\circ} \mathrm{C}$ before drilling and became $42.49^{\circ} \mathrm{C}$ after drilling whereas in the conventional method group, the mean temperature was $37.64^{\circ} \mathrm{C}$ before drilling and $41.07^{\circ} \mathrm{C}$ after drilling.

Table 1. Descriptive statistics of the variables in terms of temperature $\left[{ }^{\circ} \mathrm{C}\right]$ before and after drilling

\begin{tabular}{|c|c|c|c|c|c|c|c|}
\hline \multicolumn{2}{|c|}{ Variable } & Status & Counts & $M$ & $S D$ & Min & Max \\
\hline \multirow{4}{*}{ Implantation method } & surgical guide & \multirow{2}{*}{ before drilling } & 40 & 38.14 & 1.14 & 35.3 & 39.8 \\
\hline & conventional & & 40 & 37.64 & 0.88 & 34.9 & 38.9 \\
\hline & surgical guide & \multirow{2}{*}{ after drilling } & 40 & 42.49 & 1.87 & 39.5 & 45.4 \\
\hline & conventional & & 40 & 41.07 & 1.98 & 37.1 & 43.8 \\
\hline \multirow{8}{*}{ Drill length } & 6-millimeter & \multirow{4}{*}{ before drilling } & 20 & 36.47 & 0.89 & 34.9 & 38.5 \\
\hline & 8-millimeter & & 20 & 38.09 & 0.43 & 37.2 & 38.9 \\
\hline & 10-millimeter & & 20 & 38.39 & 0.48 & 37.4 & 39.3 \\
\hline & 12-millimeter & & 20 & 38.61 & 0.60 & 37.6 & 39.8 \\
\hline & 6-millimeter & \multirow{4}{*}{ after drilling } & 20 & 39.19 & 1.29 & 37.1 & 41.3 \\
\hline & 8-millimeter & & 20 & 41.22 & 0.60 & 40.3 & 42.2 \\
\hline & 10-millimeter & & 20 & 42.81 & 0.83 & 41.3 & 44.0 \\
\hline & 12-millimeter & & 20 & 43.91 & 1.14 & 41.5 & 45.4 \\
\hline \multirow{4}{*}{ Measurement site } & site $A$ & \multirow{2}{*}{ before drilling } & 40 & 37.84 & 1.03 & 35.3 & 39.6 \\
\hline & site B & & 40 & 37.94 & 1.07 & 34.9 & 39.8 \\
\hline & site A & \multirow{2}{*}{ after drilling } & 40 & 41.65 & 2.12 & 37.1 & 45.4 \\
\hline & site $B$ & & 40 & 41.91 & 1.98 & 37.2 & 45.3 \\
\hline
\end{tabular}

M - mean; SD - standard deviation; min - minimum; max - maximum. 
It was also noted that the temperature increased with an increasing drilling depth, with the average temperature after drilling of $39.19^{\circ} \mathrm{C}$ following the use of a 6 -millimeter drill as compared to $43.91^{\circ} \mathrm{C}$ following the use of a 12-millimeter drill.

No significant differences in temperature were observed between the opposite sides of the implant socket.

The ANOVA test was performed to study the effects of the pre-drilling temperature, the implantation method, the length of the drill, and the measurement site on the temperature recorded after drilling (Table 2).

Table 2. Association between the variables and the recorded temperature (ANOVA)

\begin{tabular}{|l|c|c|c|c|}
\multicolumn{1}{|c}{ Variable } & F-value & $p$-value & $\eta^{2}$-value & $\begin{array}{c}\text { Severity } \\
\text { of effect }\end{array}$ \\
\hline Implantation method & 66.25 & $0.001^{*}$ & 0.513 & mild \\
Drill length & 64.63 & $0.001^{*}$ & 0.755 & strong \\
Measurement site & 2.59 & 0.113 & - & - \\
Pre-drilling temperature & 10.09 & $0.002^{*}$ & 0.138 & weak \\
\hline
\end{tabular}

* statistically significant.

Table 2 highlights that no statistically significant difference was found between the temperature measurement sites on both sides of the implant socket $(p=0.113)$.

As for the remaining independent variables, significant differences in the temperature after drilling were found between all of them.

Table 3 shows the mean $(M)$ and standard error $(S E)$ values for the temperature recorded following the use of the 2 surgical implant placement methods and different length drills, on both sides of the implant socket.

Table 3. Estimated mean ( $M)$ and standard error (SE) temperature values $\left[{ }^{\circ} \mathrm{C}\right]$ for each variable

\begin{tabular}{|c|c|c|c|}
\hline \multicolumn{2}{|c|}{ Variable } & $M$ & SE \\
\hline \multirow{2}{*}{ Implantation method } & surgical guide & 42.38 & 0.10 \\
\hline & conventional & 41.18 & 0.10 \\
\hline \multirow{4}{*}{ Drill length } & 6-millimeter & 39.76 & 0.22 \\
\hline & 8-millimeter & 41.13 & 0.14 \\
\hline & 10-millimeter & 42.60 & 0.15 \\
\hline & 12-millimeter & 43.62 & 0.16 \\
\hline \multirow{2}{*}{ Measurement site } & buccal & 41.67 & 0.09 \\
\hline & lingual & 41.89 & 0.09 \\
\hline
\end{tabular}

The multiple comparison test was conducted using the Bonferroni method on the mean temperature values after drilling to compare various drill lengths, as shown in Table 4.

Significant differences in heat generation were found between any 2 drill lengths used.
Table 4. Multiple comparison between different drill lengths using the Bonferroni correction

\begin{tabular}{|cc|c|c|c|}
\hline \multicolumn{2}{|c|}{$\begin{array}{c}\text { Hole depth } \\
{[\mathrm{mm}]}\end{array}$} & $\begin{array}{c}\text { Difference between } \\
\text { the groups }\end{array}$ & SE & $p$-value \\
\hline 6 & 8 & -1.37 & 0.28 & $0.001^{*}$ \\
& 10 & -2.84 & 0.31 & $0.001^{*}$ \\
& 12 & -3.86 & 0.33 & $0.001^{*}$ \\
\hline & 10 & -1.47 & 0.19 & $0.001^{*}$ \\
10 & 12 & -2.49 & 0.20 & $0.001^{*}$ \\
\hline
\end{tabular}

* statistically significant.

\section{Discussion}

The amount of heat generated by and transmitted from burs to the bone during drilling while preparing the implant socket depends on several factors, including the speed of rotation of the drill, the number of drills used, the design and shape of the drill, the depth of drilling, the cutting edge of the drill, and the use of internal or external irrigation. To sum up, what is important with regard to heat generation are the cooling mechanisms and the forces applied during the drilling process. ${ }^{9}$ Therefore, if a surgical guide is to be used, it should have cooling channels to reduce an increase in bone temperature. This is particularly important when drilling is performed in harder bone, such as D1 or D2, since the use of a surgical guide may reduce the effectiveness of irrigation. ${ }^{10}$

The results of this study showed that there was a statistically significant effect of each of the implant placement method and drill length as well as of the temperature before drilling on the temperature values after drilling. The fact that a surgical guide hampers the access of the irrigation fluid to the drilling site may explain a significant increase in temperature in case a surgical guide is used for dental implant placement. ${ }^{7}$ The rise in temperature which occurs when the first 2.2-millimeter bur is used is due to the need to remove a large amount of bone, which causes friction to the bone during drilling. ${ }^{11}$ The clinical temperature values recorded after the bone drilling process are usually lower and safer than those recorded in laboratory studies; this might be due to the fact that the blood circulation within bone tissue dissipates a slight amount of the heat generated during the drilling process. ${ }^{12}$

A slight difference in the mean pre-drilling temperature of $0.5^{\circ} \mathrm{C}$ was noted. All bone blocks were placed in an aqueous medium of a temperature of $37^{\circ} \mathrm{C}$ in an attempt to standardize the pre-drilling temperature. However, slight differences can be expected, as the temperature of the medium can be $37 \pm 0.5^{\circ} \mathrm{C}$.

The highest temperature recorded in our study did not reach the threshold for osteonecrosis. 
These results align with the results obtained by Misir et al., who conducted their study on bone-like dental models using the Thermocouple Type K device with a drilling speed of $1,500 \mathrm{rpm} .{ }^{13}$ The researchers used 2 different systems of drilling burs: in the $1^{\text {st }}$ group, an external irrigation system was used, and in the $2^{\text {nd }}$ group, both internal and external irrigation systems were applied. The authors concluded that drilling the implant socket with the use of a surgical guide resulted in a greater increase in temperature in comparison with the conventional method. ${ }^{13}$

Moreover, the results of the present study are in line with a study by Strbac et al., where it was found that the highest increase in bone temperature was obtained after reaching the deepest point in the hole, and that heat generation was a result of friction between the bone and the drill surface. ${ }^{14}$

Our results are also consistent with those of Kim et al., who conducted their study on models of artificial bone using the Thermocouple Type $\mathrm{K}$ device, and made measurements at depths of 1,5 and $10 \mathrm{~mm} .{ }^{15}$ The authors showed that the highest internal temperature of the bone was at a depth of $10 \mathrm{~mm}\left(44 \pm 1.09^{\circ} \mathrm{C}\right) .{ }^{15}$

One of the limitations of this study was that it was done in a laboratory setting, where the recorded temperature may not be identical to that achieved in clinical conditions. Such studies are hard to perform in vivo; there would be some ethical concerns with regard to drilling 2 temperature holes in the patient's mouth, and also there would be anatomical difficulties with placing the probes intraorally. With that said, the highest temperature achieved in the current study was still lower that the threshold for bone necrosis. Therefore, it is the authors' belief that when using a good irrigation system in clinical conditions, lower and safe temperatures are expected due to the added benefit of the blood circulation. Another limitation is measuring the temperature in the temperature holes rather than the implant socket itself, although the closeness of the hole to the implant socket may reduce the amount of temperature discrepancies that might occur.

\section{Conclusions}

Within the limitations of this study, we can conclude that using a surgical guide results in a higher temperature as compared to the conventional method of implant placement, as a surgical guide can impede irrigation. However, the observed increase was not statistically significant and the highest recorded temperature was below the threshold for bone necrosis.

\section{ORCID iDs}

Khaldoun Hossein Alhroob (D) https://orcid.org/0000-0001-8683-3094 Mohammed Monzer Alsabbagh (1) https://orcid.org/0000-0003-0628-8140 Aghiad Yassin Alsabbagh (1) https://orcid.org/0000-0002-0947-4857

\section{References}

1. Tsoukaki M, Kalpidis CDR, Sakellari D, Tsalikis L, Mikrogiorgis G, Konstantinidis A. Clinical, radiographic, microbiological, and immunological outcomes of flapped vs. flapless dental implants: A prospective randomized controlled clinical trial. Clin Oral Implant Res. 2013;24(9):969-976. doi:10.1111/j.1600-0501.2012.02503.x

2. Vieira DM, Sotto-Maior BS, Villaça de Souza Barros CA, Reis ES, Francischone CE. Clinical accuracy of flapless computer-guided surgery for implant placement in edentulous arches. Int J Oral Maxillofac Implant. 2013;28(5):1347-1351. doi:10.11607/jomi.3156

3. Nikzad S, Azari A, Ghassemzadeh A. Modified flapless dental implant surgery for planning treatment in a maxilla including sinus lift augmentation through use of virtual surgical planning and a 3-dimensional model. J Oral Maxillofac Surg. 2010;68(9):2291-2298. doi:10.1016/j.joms.2010.02.002

4. Jeong SM, Choi BH, Kim J, et al. A 1-year prospective clinical study of soft tissue conditions and marginal bone changes around dental implants after flapless implant surgery. Oral Surg Oral Med Oral Pathol Oral Radiol Endod. 2011;111(1):41-46. doi:10.1016/j.tripleo.2010.03.037

5. Cunha RM, Souza FÁ, Hadad H, Poli PP, Maiorana C, Perri Carvalho PS. Accuracy evaluation of computer-guided implant surgery associated with prototyped surgical guides. J Prosthet Dent. 2021;125(2):266-272. doi:10.1016/j.prosdent.2019.07.010

6. Dreiseidler T, Neugebauer J, Ritter L, et al. Accuracy of a newly developed integrated system for dental implant planning. Clin Oral Implants Res. 2009;20(11):1191-1199. doi:10.1111/j.1600-0501.2009.01764.x

7. Frösch L, Mukaddam K, Filippi A, Zitzmann NU, Kühl S. Comparison of heat generation between guided and conventional implant surgery for single and sequential drilling protocols - An in vitro study. Clin Oral Implant Res. 2019;30(2):121-130. doi:10.1111/clr.13398

8. Eriksson AR, Albrektsson T. Temperature threshold levels for heatinduced bone tissue injury: A vital-microscopic study in the rabbit. J Prosthet Dent. 1983;50(1):101-107. doi:10.1016/0022-3913(83)90174-9

9. Scarano A, Lorusso F, Noumbissi S. Infrared thermographic evaluation of temperature modifications induced during implant site preparation with steel vs. zirconia implant drill. J Clin Med. 2020;9(1):148. doi:10.3390/jcm9010148

10. Liu YF, Wu JL, Zhang JX, Peng W, Liao WQ. Numerical and experimental analyses on the temperature distribution in the dental implant preparation area when using a surgical guide. J Prosthodont. 2018;27(1):42-51. doi:10.1111/jopr.12488

11. Sannino G, Gherlone EF. Thermal changes during guided flapless implant site preparation: A comparative study. Int J Oral Maxillofac Implants. 2018;33(3):671-677. doi:10.11607/jomi.6029

12. Bogovič V, Svete A, Bajsić I. Effects of a drill diameter on the temperature rise in a bone during implant site preparation under clinical conditions. Proc Inst Mech Engin H. 2016;230(10):907-917. doi:10.1177/0954411916660737

13. Misir AF, Sumer M, Yenisey M, Ergioglu E. Effect of surgical drill guide on heat generated from implant drilling. J Oral Maxillofac Surg. 2009;67(12):2663-2668. doi:10.1016/j.joms.2009.07.056

14. Strbac GD, Giannis K, Unger E, Mittlböck M, Watzek G, Zechner W. A novel standardized bone model for thermal evaluation of bone osteotomies with various irrigation methods. Clin Oral Implants Res. 2014;25(5):622-631. doi:10.1111/clr.12090

15. Kim Y, Ju S, Kim MJ, Park M, Jun S, Ahn J. Direct measurement of heat produced during drilling for implant site preparation. Appl Sci. 2019;9(9):1898. doi:10.3390/app9091898 